\title{
Creating Cavities at Palladium-Phosphine Interfaces for Enhanced Selectivity in Heterogeneous Biomass Conversion
}

\author{
Manuel A. Ortuño*(๑) and Núria López*(1) \\ Institute of Chemical Research of Catalonia, ICIQ, and the Barcelona Institute of Science and Technology, BIST, Av. Països Catalans \\ 16, 43007 Tarragona, Spain
}

Supporting Information

\begin{abstract}
Selective conversion of biomass-derived substrates in heterogeneous catalysis can be achieved through the functionalization of nanoparticles with surface modifiers (ligands). However, full understanding of reaction mechanisms at the atomic level of detail is still limited. Herein we rely on computational approaches to address this challenge. We employ Density Functional Theory to understand the role of phosphine-decorated palladium nanoparticles in the decarbonylation of fatty acids to produce linear $\alpha$-olefins. While self-assembled monolayers of monodentate ligands completely passivate the metal surface, the flexibility of bidentate counterparts allows the creation of transient cavities that: (i) enhance selectivity and (ii) prevent catalyst deactivation. Such detailed insight provided by theory can pave the way for a rational design of metal-ligand interfaces in biomass upgrading.
\end{abstract}

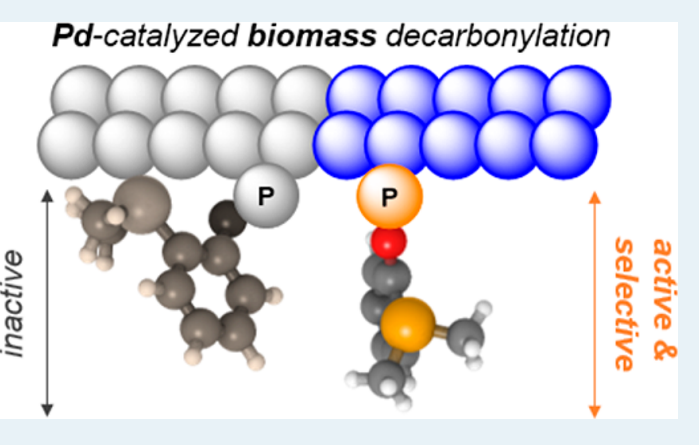

KEYWORDS: biomass, decarbonylation, density functional theory, metal-ligand interfaces, palladium, phosphine, selectivity

\section{INTRODUCTION}

Industrial processes are mainly dominated by heterogeneous catalysis. Nevertheless, the excellent activity and recyclability of these systems are sometimes tainted by poor selectivity. As a result, current efforts are heavily focused on the chemistry at the interface between metal nanoparticles and surface modifiers. ${ }^{1,2}$ The resulting ligand-decorated systems combine the advantages of heterogeneous systems with the selectivity of homogeneous counterparts. ${ }^{3}$ The most successful example is the selective semihydrogenation of alkynes using the Lindlar catalyst, consisting of $\mathrm{Pd} / \mathrm{CaCO}_{3}$, lead, and quinoline. ${ }^{4}$ More recently, the functionalization of metals with NanoSelect is producing highly active and selective nanostructured catalysts for a wide variety of applications. ${ }^{5}$ Selective modifiers ${ }^{6,7}$ can potentially: (i) block the catalytic site on the surface area thus controlling the catalytic ensemble, (ii) alter the properties of the metal-ligand boundaries, such as acidity, ${ }^{8}$ and (iii) impose steric and electronic effects ${ }^{9-11}$ on reactants and products.

Due to their potential recyclability and selectivity, liganddecorated nanoparticles find a straightforward application on biomass upgrading, ${ }^{12,13}$ where selective deoxygenation is the key step. ${ }^{14-16}$ With readily available sources of vegetable oils and animal fats, we focus on the decarbonylation of fatty acids to yield linear $\alpha$-olefins (LAOs), ${ }^{17}$ which are valuable materials in a myriad of applications, such as comonomers in polymerizations and precursors of surfactants and lubricants, among others. ${ }^{18}$ LAOs are usually prepared via ethylene oligomerization $^{19,20}$ or Fischer-Tropsch processes, ${ }^{21}$ but the use of fatty acids allows direct access to odd numbered derivatives, which would be more expensive and less trivial to prepare otherwise.
One big challenge of such a process is selectivity, in particular, precluding isomerization of the terminal alkene to the thermodynamically favored internal one (Scheme 1). Most

Scheme 1. Decarbonylation of Fatty Acids to Olefins via Ester or Anhydride Intermediates

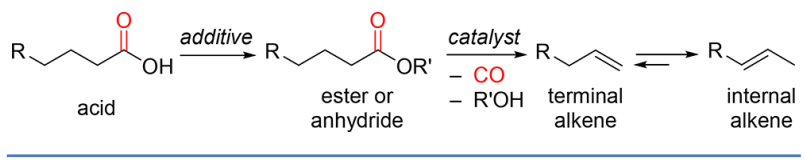

homogeneously catalyzed systems are based on $\mathrm{Pd}-$ phosphine complexes and proceed through ester or anhydride intermediates. ${ }^{22-30}$ In some cases, isomerization could be prevented by fine-tuning of ligands, ${ }^{24,29,30}$ but $\mathrm{CO}$ inhibition might also become an issue. ${ }^{31}$

Despite this early success, homogeneous catalysts lack recyclability, so the design of heterogeneous counterparts becomes quite appealing for industrial applications. Initial studies employed $\mathrm{H}_{2}$ as coreactant, but that leads to product hydrogenation. ${ }^{32-36}$ Less attention has been drawn to $\mathrm{H}_{2}$-free heterogeneous deoxygenation systems, ${ }^{16}$ where anhydrides have also been invoked as key intermediates. ${ }^{37}$ Recent reports on decarbonylation processes are promising but still present low selectivity toward LAOs. ${ }^{38-40}$ 
Inspired by homogeneous systems, Chatterjee and Jensen ${ }^{41}$ designed $\mathrm{Pd} / \mathrm{C}$ catalysts functionalized with phosphine ligands. Interestingly, while the clean and monodentate-phosphine catalysts were inactive, the addition of bidentate phosphines completely changed the picture. At $250{ }^{\circ} \mathrm{C}$, they obtained reasonable yields, LAO selectivities up to $98 \%$, and no reactivity coming from leached species. Indeed, pioneer works by Fujihara and co-workers already reported Pd nanoparticles functionalized with bidentate phosphines for catalytic applications. $^{42,43}$ In light on these experiments, we designed a computational study to address the $\mathrm{Pd}$-phosphine interface at atomic level of detail to provide insight on activity and selectivity. Mechanistic studies have been reported for molecular catalysts, ${ }^{30,44,45}$ and Heyden and co-workers have extensively studied the decarbonylation of propanoic acid ${ }^{46-49}$ and methyl propionate ${ }^{50,51}$ over $\operatorname{Pd}(111), \operatorname{Pd}(211),{ }^{52,53}$ and $\mathrm{Ru}(0001) .{ }^{54}$ Some reports on adsorption of phosphines on Pd surfaces ${ }^{55}$ and nanoclusters ${ }^{56}$ exist, but little is known on how the reaction mechanism proceeds at such interfaces. To the best of our knowledge, this is the first computational approach of phosphine-decorated metal surfaces that fully addresses reactivity features at different coverages. Just a few reactivity studies can be found for P-functionalized Au-based systems. ${ }^{57-59}$

Herein we simulate the decarbonylation of fatty acid derivatives to olefins on clean and phosphine-decorated Pd surfaces to unravel the role of ligands on activity and selectivity (Figure 1). We use pentanoic acid as model substrate to mimic

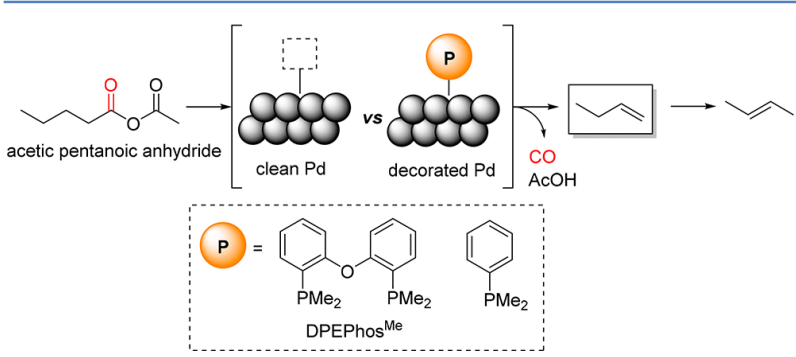

Figure 1. Heterogeneous Pd-catalyzed decarbonylation reaction under study.

long aliphatic chains. The product, 1-butene, is large enough to study the isomerization side reaction. As for ligands, we use DPEPhos $^{\mathrm{Me}}$ based on the best performing bidentate DPEPhos, and $\mathrm{PPhMe}_{2}$ for the inactive monodentate $\mathrm{PPh}_{3}$ (Figure 1), as experimentally reported. ${ }^{41}$

\section{COMPUTATIONAL DETAILS}

All calculations were performed at the Density Functional Theory (DFT) level of theory using the Vienna Ab-initio Simulation Package (VASP). ${ }^{60,61}$ The PBE functional ${ }^{62}$ was employed together with Grimme's D2 dispersion scheme ${ }^{63}$ and our modified parameters for transition metals. ${ }^{64}$ Core electrons were described by projector augmented wave (PAW) pseudopotentials ${ }^{65}$ and valence electrons were represented by plane waves with a kinetic energy cutoff of $450 \mathrm{eV}$, as in previous related studies. ${ }^{8,46,50,59}$ Large Pd nanoparticles ( 20 $\mathrm{nm}$ diameter $)^{41}$ were described using $\operatorname{Pd}(111)$ slabs. We prepared $\mathrm{p}(4 \times 4), \mathrm{p}(5 \times 5)$, and $\mathrm{p}(6 \times 6)$ models to accommodate reactants and ligands. We used four-layer thick slabs, where the two upper layers were relaxed, and the two bottom ones were fixed to mimic the bulk. All reactants and ligands were fully relaxed during geometry optimizations. The Brillouin zone for the $\mathrm{p}(4 \times 4), \mathrm{p}(5 \times 5)$, and $\mathrm{p}(6 \times 6)$ slabs was sampled by a $3 \times 3 \times 1,2 \times 2 \times 1$, and $2 \times 2 \times 1 k$-points mesh, respectively, generated through the Monkhorst-Pack method. ${ }^{66}$ Density of states (DOS) were obtained with a denser $5 \times 5 \times 1 k$-points mesh. To avoid spurious interactions between the periodic images, a vacuum region between the slabs of $15 \AA$ and dipole correction along $\mathrm{z}$ were included. ${ }^{67}$ Transition states (TSs) were located with the climbing image nudged elastic band ${ }^{68}$ and improved dimer ${ }^{69}$ methods. The assessment of the minima and transition states was performed by diagonalizing the numerical Hessian matrix obtained by $\pm 0.015 \AA$ displacements (metal and ligand atoms were fixed during frequency calculations). Normal modes associated with TS imaginary frequencies correspond with the chemical step described. Vibrational partition functions were computed for selected species using numerical frequencies ( $\Gamma$-point) where all nonmetal atoms were relaxed (at $523 \mathrm{~K}$ ). All frequencies below $200 \mathrm{~cm}^{-1}$ were replaced by $200 \mathrm{~cm}^{-1}$. ${ }^{70}$ All inputs and final structures can be found in the ioChem-BD repository. ${ }^{71,72}$ $3 \mathrm{D}$ representations were prepared with the QuteMol visualization package. $^{73}$

\section{RESULTS AND DISCUSSION}

We first present mechanistic studies using clean $\operatorname{Pd}(111)$ surfaces at low reactant coverage, $\mathbf{A}$, and high reactant coverage, B. We then characterize phosphine-decorated $\mathrm{Pd}(111)$ surfaces, C, and evaluate them as potential active species during the catalytic cycle.

Reactivity on Clean Pd(111). Initially, we assume the in situ formation of acetic pentanoic anhydride ${ }^{37}$ through the reaction of pentanoic acid with acetic anhydride. Similar to previous literature, ${ }^{46}$ we compute the decarbonylation mechanism of one acetic pentanoic anhydride molecule on a clean $\operatorname{Pd}(111)$ surface $\mathbf{A}$ that minimizes close contacts between neighbors (i.e., a low coverage situation). The energy profile is presented in Figure 2. Initial adsorption of the anhydride is exothermic by $0.81 \mathrm{eV},^{74,75}$ where the aliphatic chain is interacting with the surface. The $\mathrm{C}-\mathrm{O}$ bond breaking process has a barrier of $0.47 \mathrm{eV}$ via TS-A1 and gives rise to the acyl intermediate $\mathbf{A 2}$ and adsorbed acetate $(-1.49 \mathrm{eV})$. The

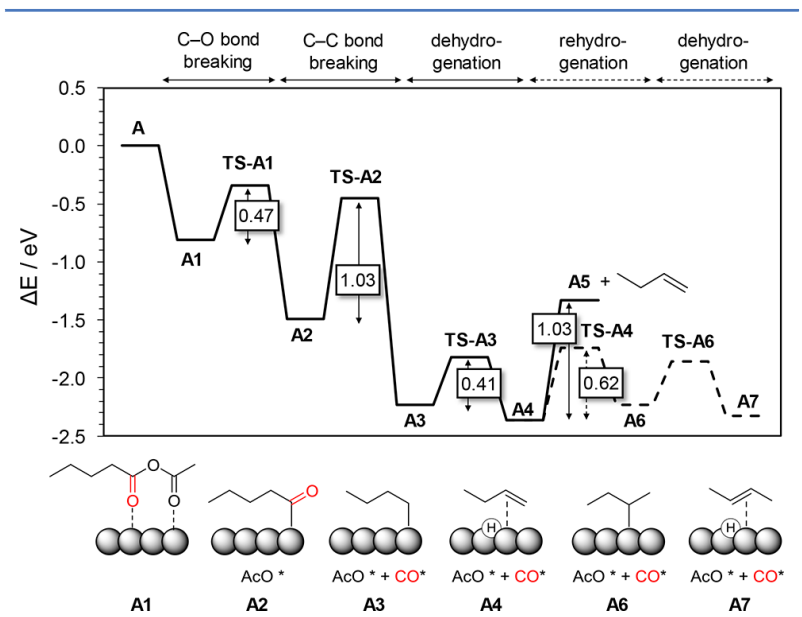

Figure 2. Decarbonylation (solid black line) and isomerization (dashed black line) mechanisms on clean $\operatorname{Pd}(111)$ A surfaces. Asterisks represent adsorbed species. 
subsequent $\mathrm{C}-\mathrm{C}$ bond breaking entails $1.03 \mathrm{eV}$ via TS-A2 and produces the alkyl intermediate $\mathbf{A} 3$ and $\mathrm{CO}(-2.23 \mathrm{eV})$. An alternative mechanism involving $\alpha$-carbon dehydrogenation ${ }^{46}$ can be consulted in Figure S1 of the Supporting Information (SI). Then, A3 quickly undergoes dehydrogenation via TS-A3 with a barrier of $0.41 \mathrm{eV}$. Alkene release from A4 to A5 takes $1.03 \mathrm{eV}$, but terminal (A4) to internal (A7) alkene isomerization appears as a competitive process with a barrier of 0.62 $\mathrm{eV}$ via TS-A4.

The energy profile estimates an overall energy barrier of 1.03 $\mathrm{eV}$ and predicts a rather facile alkene isomerization involving $0.62 \mathrm{eV}$. At $250{ }^{\circ} \mathrm{C}$, the reaction temperature, such barriers should be easy to overcome. However, catalytic runs using clean $\mathrm{Pd} / \mathrm{C}$ (i.e., in the absence of phosphine ligands) report no reaction with recovery of starting materials. ${ }^{41}$

According to experiments, $\mathrm{Pd}$ is added in $1 \% \mathrm{~mol}$ and the resulting nanoparticles are very large $(\sim 20 \mathrm{~nm}$ diameter $)$. Therefore, we would expect a large ratio between reactants and accessible (first surface layer) Pd atoms; in other words, a high coverage scenario. We then assume that acid molecules first cover the Pd surface, as acetic anhydride is added in a later step. ${ }^{41}$ We design a $\mathrm{p}(4 \times 4) \mathrm{Pd}(111)$ slab B (Figure 3) with

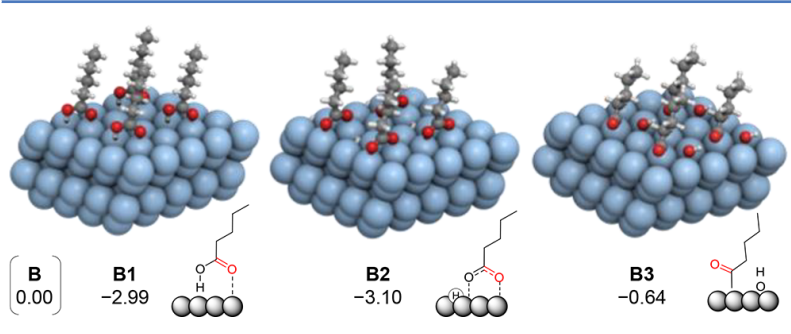

Figure 3. Adsorption energies $(\mathrm{eV})$ of all four molecules for the high coverage model $\mathbf{B}$. $(\mathrm{Pd}=$ light blue, $\mathrm{O}=$ red, $\mathrm{C}=$ gray, $\mathrm{H}=$ white $)$.

four pentanoic acid molecules B1 to model a self-assembled monolayer (SAM). The adsorption of reactants is highly exothermic at $-2.99 \mathrm{eV}^{76}$ The adsorption energy per acid molecule, $-0.75 \mathrm{eV}$, is similar to that of a single anhydride molecule in A1, $-0.81 \mathrm{eV}$. The acidic hydrogen of the $\mathrm{OH}$ group dissociates to form $\mathbf{B} 2$ at $-3.10 \mathrm{eV}$. These values suggest that the initial full coverage of Pd by acid molecules might prevent further reaction with the acetic anhydride coreactant. Moreover, the $\mathrm{C}-\mathrm{O}$ bond breaking step to access the key acyl intermediate, B3, is significantly endothermic, demanding 2.46 $\mathrm{eV}$ above B2. According to these results, the excess of acid prevents the decarbonylation step from a thermodynamic point of view, thus no alkene product should be observed.

Phosphine Self-Assembled Monolayers on $\mathrm{Pd}(111)$. Due to the large excess of reactant and ligand molecules compared to accessible metal atoms, we would expect a full coverage of Pd surfaces. The characterization of SAMs is quite important as such high coverage situations decide the fate of the active sites of the catalyst. ${ }^{79}$ As seen below, the adsorption of phosphines is preferred over acid molecules, thus we design a model to reproduce phosphine SAMs over Pd.

We first calculate the interaction of different phosphines $\left(\mathrm{PMe}_{3}, \mathrm{PPhMe}_{2}, \mathrm{PPh}_{3}\right.$, and DPEPhos $\left.{ }^{\mathrm{Me}}\right)$ with $\mathrm{p}(5 \times 5)$ $\operatorname{Pd}(111)$ to evaluate the contributions of ligands to the adsorption energy. $\mathrm{PMe}_{3}$ binds to the surface through the $\mathrm{P}$ atom with an energy of $-2.33 \mathrm{eV}$, and $\mathrm{PPhMe}_{2}$ does the same through the $\mathrm{P}$ atom and the phenyl group with an energy of $-3.54 \mathrm{eV}$. These data indicate that the major contribution is coming from the formation of $\mathrm{Pd} \cdots \mathrm{P}$ interactions, although phenyl adsorption is also significant. Interestingly, differences in hydrogenation activity for aryl- and alkyl-derived phosphines have been noted in $\mathrm{Ru}$-decorated nanoparticles. ${ }^{78}$ The adsorption energy of $\mathrm{PPh}_{3}(-3.73 \mathrm{eV})$ is quite similar to that of $\mathrm{PPhMe}_{2}(-3.54 \mathrm{eV})$. Lastly, the bidentate DPEPhos ${ }^{\mathrm{Me}}$ binds to the surface through two $\mathrm{P}$ atoms and one phenyl group, and thus an expected larger adsorption energy of $-4.77 \mathrm{eV}$ is found.

To properly design a model for a high coverage scenario, we now adsorb up to two DPEPhos ${ }^{\mathrm{Me}}$ ligands on different $\operatorname{Pd}(111)$ slab sizes. Adsorption of one ligand on $p(4 \times 4), p(5 \times 5)$, and $\mathrm{p}(6 \times 6)$ takes $-3.56,-4.77$, and $-4.83 \mathrm{eV}$, respectively. Looking at adsorption energies per area, we obtain -0.033 , -0.029 , and $-0.020 \mathrm{eV} \AA^{-2}$, respectively. We then add an additional ligand molecule to these slab models. While the second phosphine does not fit on $\mathrm{p}(4 \times 4)$, it does on $\mathrm{p}(5 \times 5)$ and $\mathrm{p}(6 \times 6)$ with overall adsorption energies of -8.80 and $-9.30 \mathrm{eV}$, respectively, and overall adsorption energies per area of -0.053 and $-0.039 \mathrm{eV} \AA^{-2}$, respectively. The adsorption energies of two bidentate phosphines are less than twice that of one, so we expect no cooperative effect between ligands. According to energetics, the $\mathrm{p}(5 \times 5)$ slab with two phosphine ligands arises as the most stable structure at high coverage, and we therefore use this model for our following studies.

Figure 4 depicts the $\mathrm{Pd}(111)$ surface with two DPEPhos ${ }^{\mathrm{Me}}$ ligands, namely $\mathbf{C}$. Interestingly, these phosphines completely

(a)
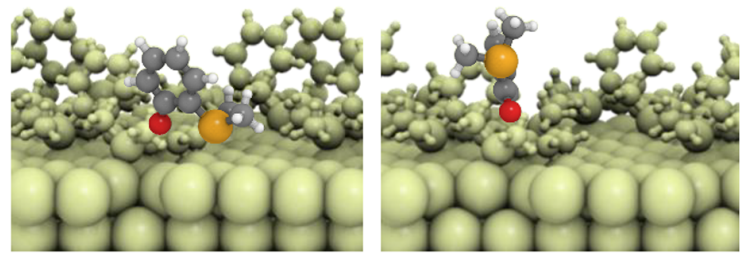

(b)
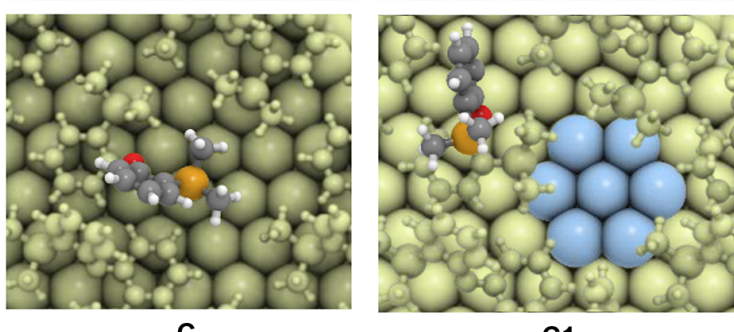

C1

Figure 4. Side (a) and top (b) views of fully coordinated C (left) and partially coordinated C1 (right) surfaces with DPEPhos ${ }^{\mathrm{Me}}$. (Accessible $\mathrm{Pd}=$ light blue, $\mathrm{P}=$ orange, $\mathrm{O}=$ red, $\mathrm{C}=$ gray, $\mathrm{H}=$ white).

cover the metal surface and block access to reactants molecules. At this stage, we propose a partial decoordination ${ }^{79,80}$ of one of the phosphine arms to create a cavity, or binding pocket, on the surface. The proposed structure, C1 in Figure 4, was found at $1.24 \mathrm{eV}^{81}$ above $\mathbf{C}$ and should be accessible under experimental conditions $\left(250{ }^{\circ} \mathrm{C}\right) .^{82}$ Indeed, the hemilabile behavior of these ligands have been reported in homogeneous systems. ${ }^{30,83}$ In the gas phase, the relaxed conformation of the phosphine coming from $\mathrm{C} 1$ is only $0.20 \mathrm{eV}$ less stable than that coming from C. It is clear than the energy toll essentially emerges from the loss of $\mathrm{Pd} \cdots \mathrm{P}$ and $\mathrm{Pd} \cdots \mathrm{C}$ interactions after partial decoordination. Additionally, starting from the DPEPhos ${ }^{\mathrm{Me}}$ model, we included two $\mathrm{Ph}$ groups in the $\mathrm{P}$ atom that detaches from the surface to better mimic the complete DPEPhos ligand. The energy difference between these species, $\mathbf{D}$ and $\mathbf{D 1}$, is now $0.85 \mathrm{eV}$. 
This value is somehow lower than that of DPEPhos ${ }^{\mathrm{Me}}$ species $\mathbf{C}$ and $\mathrm{C1}(1.24 \mathrm{eV})$. This result might be related to: (i) the slightly more electron-donor character of alkyl phosphine (C) compared to aryl ones (D) and (ii) the liberation of bulkier Ph groups (cf. Me).

An interesting feature of experiments is that systems containing monodentate phosphines, such as $\mathrm{PPh}_{3}$, do not perform well. ${ }^{41}$ Thus, we also modeled a SAM of $\mathrm{PPhMe}_{2}$ as model for $\mathrm{PPh}_{3}$. Using the same $\mathrm{p}(5 \times 5)$ as before, we adsorb three ligands to obtain a fully covered surface, E. In contrast to $\mathrm{C}$, which only requires partial decoordination to expose surface atoms in $\mathrm{C1}$ via $1.24 \mathrm{eV}, \mathrm{E}$ requests the full desorption of one $\mathrm{PPhMe}_{2}$ ligand via $2.61 \mathrm{eV}$ to form E1. Even though the latter process should be entropically favored, it is still quite demanding compared to that involving the bidentate ligand.

To sum up, the lack of flexibility of monodentate phosphines explains the poor catalytic performance of these systems, since the metal surface is essentially poisoned by these ligands. However, the chelating features of bidentate phosphines allow the creation of transient cavities at the metal-ligand interface. In the next section, we will evaluate whether such surface sites, as those found in $\mathbf{C 1}$, are active and kinetically relevant during the catalytic cycle.

Reactivity on Phosphine-Decorated Pd(111). Similarly to clean $\mathrm{Pd}(111)$ (Figure 2), we compute the decarbonylation mechanism of acetic pentanoic anhydride to 1-butene on a phosphine-decorated $\operatorname{Pd}(111)$ surface. Since the adsorption energy of the phosphine is significantly larger than that of the acid, the metal surface is first covered by phosphine ligands, allowing fatty acids to react with acetic anhydride to form mixed anhydride intermediates. ${ }^{37}$ The energy profile is shown in Figure 5, where we consider the previously discussed C1

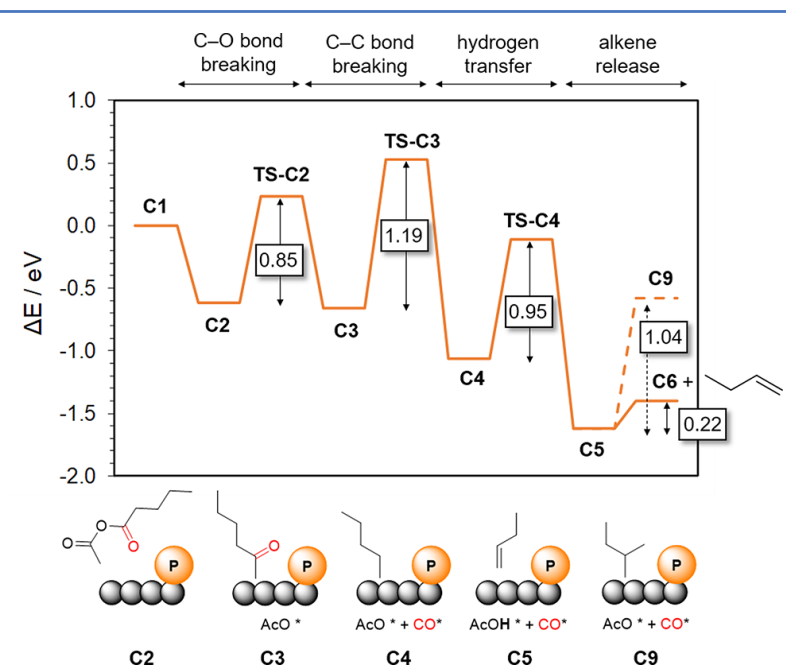

Figure 5. Decarbonylation (orange line) and isomerization (dashed orange line) mechanisms on phosphine-decorated $\mathrm{Pd}(111) \mathrm{C}$ surfaces. Asterisks represent adsorbed species.

structure as starting point. Adsorption of pentanoic anhydride forms C2 at $-0.62 \mathrm{eV}$. Due to the constrained pocket, the aliphatic chain does not interact with the metal surface but the organic groups from the nearby ligands. The $\mathrm{C}-\mathrm{O}$ bond breaking of the anhydride (and concomitant formation of acetate) via TS-C2 involves $0.85 \mathrm{eV}$. The resulting acyl intermediate $\mathrm{C} 3$ goes through a $\mathrm{C}-\mathrm{C}$ bond breaking process via TS-C3 (Figure 6 left) with a barrier of $1.19 \mathrm{eV}^{84}$ to produce
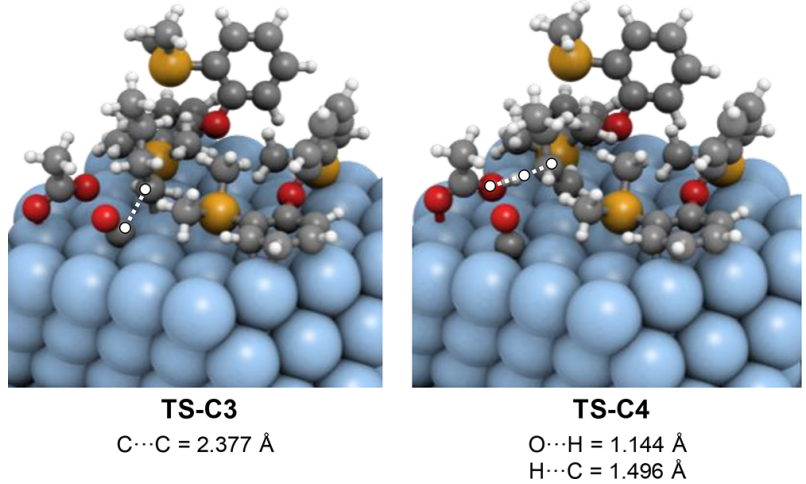

Figure 6. Transition states TS-C3 (C-C bond breaking) and TS-C4 (hydrogen transfer) for the phosphine-decorated $\operatorname{Pd}(111) \mathrm{C}$ surface. ( $\mathrm{Pd}=$ light blue, $\mathrm{P}=$ orange, $\mathrm{O}=$ red, $\mathrm{C}=$ gray, $\mathrm{H}=$ white). Key distances are shown with dashed white lines.

C4 and CO. ${ }^{85}$ The alkyl intermediate should then undergo dehydrogenation to form the corresponding olefin product. However, hydrogen transfer from the alkyl group to the metal surface appears to be challenging ${ }^{86}$ as most of $\mathrm{Pd}$ atoms are already interacting with adsorbed species (phosphines, acetate, or $\mathrm{CO}$ ). Instead, the acetate bound to the surface acts as an internal base ${ }^{44}$ and deprotonates the alkyl group via TS-C4 (Figure 6 right) with a barrier of $0.95 \mathrm{eV}$. Quite remarkably, the resulting alkene product $\mathbf{C 5}$ does not bind in a parallel fashion as in the clean surface (A4 and A7, Figure 2). Due to the steric hindrance imposed by the phosphine cavity, the $\pi$-system is found perpendicular to the surface, and the alkene desorption via C6 becomes essentially barrierless ( $0.22 \mathrm{eV}$ above C5). Alkene isomerization would entail the transient formation of a secondary alkyl intermediate (analogue to A6). Such structure, C9, is found at $1.04 \mathrm{eV}$ above C5, which further rules out the isomerization process.

Discussion. We find three major differences between the energy profiles of clean A (Figure 2) and phosphine-decorated C (Figure 5) systems. First, the $\mathrm{C}-\mathrm{C}$ bond scission via TS-A2 demands $1.03 \mathrm{eV}$, while the same process via TS-C3 takes 1.19 $\mathrm{eV}$. The larger energy barrier for system $\mathrm{C}$ is in line with the presence of ligands on the surface; in other words, the metal atoms on the surface are more coordinated and, therefore, less reactive. This is nicely reflected on the higher Pd $d$-band center $^{87,88}$ of clean $\mathbf{A},-1.77 \mathrm{eV}$, compared to that of phosphine-decorated $\mathrm{Cl},-1.84 \mathrm{eV}$. In the same line, the dehydrogenation via TS-A3 $(0.41 \mathrm{eV})$ is significantly less demanding than the acetate-assisted hydrogen transfer via TSC4 $(0.95 \mathrm{eV})$. This is yet another feature of the highly functionalized surface, where little room is left for hydrogen adsorption on the decorated surface. Finally, we observe an opposite trend for the alkene desorption step. Clean $\mathbf{A}$ releases 1-butene via $1.03 \mathrm{eV}$ and isomerizes it to 2-butene via $0.62 \mathrm{eV}$, while phosphine-decorated $\mathbf{C 1}$ desorbs the alkene in a barrierless step. The steric hindrance of the metal-phosphine interface pushes away the product and plays a beneficial role driving the reaction toward the linear $\alpha$-olefin.

Previous DFT studies in homogeneous Pd catalysts ${ }^{30,44}$ suggested dehydrogenations as rate-determining TSs, while the present work on $\mathrm{Pd}(111)$ surfaces points toward the $\mathrm{C}-\mathrm{C}$ bond breaking process (TS-C3). Interestingly, the relative activation energies for dehydrogenation (from the prior alkyl intermediate to the corresponding TS) are quite similar for 
both systems, i.e., $1.05 \mathrm{eV}$ in ref 44 and $0.95 \mathrm{eV}$ from $\mathrm{C} 4$ to TSC4. The main difference thus comes from the ability of metal surfaces to stabilize alkyl intermediates. While the formation of alkyl intermediates is systematically endothermic in molecular catalysts $(+0.33 \mathrm{eV}$ in ref 44$)$, that process is exothermic on $\mathrm{Pd}(111)$ surfaces $(-0.74 \mathrm{eV}$ from $\mathbf{A} 2$ to $\mathbf{A} 3$ and $-0.40 \mathrm{eV}$ from C3 to C4). In other words, the highest point of homogeneous energy profiles usually corresponds to the dehydrogenation step due to the energy penalty required to form unstable alkyl intermediates.

We then consider the role of the ligand in catalyst deactivation. ${ }^{89}$ The major byproduct of the reaction is $\mathrm{CO}$, which is known to bind strongly to $\mathrm{Pd}$. As expected, direct $\mathrm{CO}$ release from $\mathrm{A} 4$ requires $2.29 \mathrm{eV}$. This poison effect is indeed similar to that for $\mathrm{PPhMe}_{2}$ release $(2.61 \mathrm{eV})$ but still significantly larger than that for DPEPhos ${ }^{\mathrm{Me}}$ partial decoordination $(1.24 \mathrm{eV})$. For phosphine-decorated surfaces, we also considered $\mathrm{CO}$ release in an earlier stage of the reaction, that is, after the formation of the alkyl intermediate C4. However, this desorption energy was still large, $2.00 \mathrm{eV}$ (Figure 7, left). Thus,

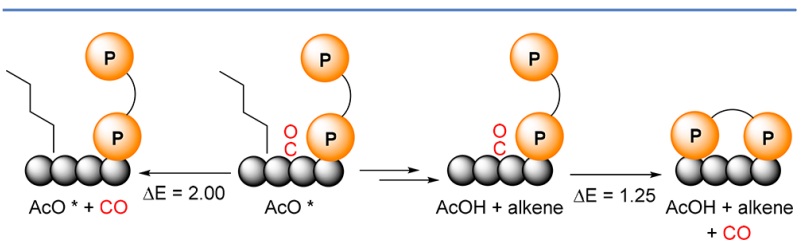

Figure 7. $\mathrm{CO}$ release $(\mathrm{eV})$ on phosphine-decorated $\mathrm{Pd}(111) \quad \mathrm{C}$ surfaces.

in the presence of bidentate ligands, we propose a displacement of $\mathrm{CO}$ by the dangling phosphine arm. The CO-by-P exchange in the phosphine-decorated system only takes $1.25 \mathrm{eV}$ (Figure 7 , right), in line with the experimental detection of $\mathrm{CO}$ under reaction conditions. ${ }^{41}$

These general concepts on decorated surfaces can impact other biomass-related processes. ${ }^{90-92}$ Looking into the related furfural decarbonylation (Figure 8), we predict a barrier of 0.59

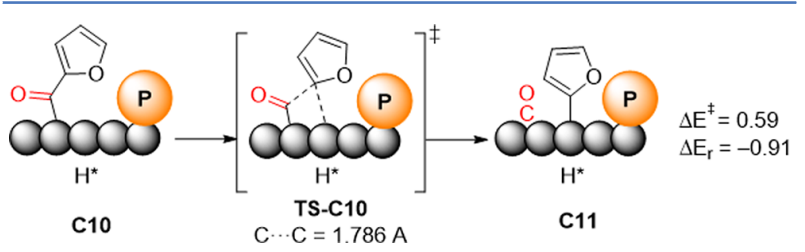

Figure 8. Furfural decarbonylation step $(\mathrm{eV})$ on phosphine-decorated $\mathrm{Pd}(111) \mathrm{C}$ surfaces.

$\mathrm{eV}$ for the $\mathrm{C}-\mathrm{C}$ bond scission step at the $\mathrm{Pd}-$ phosphine interface in $\mathbf{C 1}$, which is comparable to previous data on clean $\mathrm{Pd}\left(0.68 \mathrm{eV}^{93,94}\right)$. In this scenario, we also expect an enhanced $\mathrm{CO}$ release promoted by bidentate phosphines (Figure 7, right), which might prevent deactivation channels via $\mathrm{CO}$ poisoning.

Overall, we identify two main roles of bidentate ligands: (i) creation of reactive pockets that avoid alkene coordination and enhance selectivity, and (ii) displacement of $\mathrm{CO}$, which attenuates surface $\mathrm{CO}$ poisoning and drives the reaction toward high conversions. On the basis of these results we enunciate some qualitative guiding rules to design metalphosphine interfaces: (i) ligand adsorption should predominate over reactant adsorption on the metal surface to ensure that ligands are not released during operation; ${ }^{80,95}$ (ii) a dynamic bidentate ligand is necessary to avoid complete passivation of the surface as found for monodentate derivatives; and (iii) sizable yet labile groups attached to phosphorus are recommended, so the freshly formed cavity is large enough to bind reactant molecules.

Homogeneous catalysis usually focuses on fine-tuning of ligands. In that sense, we devise that other bidentate ligands, such as those reported for Pd-catalyzed carbonylation of olefins, ${ }^{96,97}$ might be of relevance for these types of transformations. However, heterogeneous catalysis mostly performs screening of metal surfaces. ${ }^{98}$ In this work, we identify the need for a rational design of interfaces to control both activity and selectivity. Current efforts are underway in our laboratories.

\section{CONCLUSIONS}

In this contribution, we have computationally elucidated the role of phosphine-decorated $\mathrm{Pd}(111)$ catalysts in biomassderived decarbonylation transformations. Self-assembled monolayers of monodentate phosphines block the metal surface, in line with the poor activity experimentally observed. On the contrary, the inherent dynamics of bidentate ligands allows the creation of transient cavities that are kinetically relevant in the catalytic cycle. These highly crowded surface sites induce a rapid product release and preclude undesired side reactions. The flexibility of phosphine arms further promotes CO desorption, thus reducing surface poisoning. The unique nature of these systems holds promise for a rational design of metalligand interfaces and applications to other biomass-related processes.

\section{ASSOCIATED CONTENT}

S Supporting Information

Alternative mechanism on $\mathbf{A}$, energies and coordinates (PDF)

\section{AUTHOR INFORMATION}

\section{Corresponding Authors}

*E-mail: mortuno@iciq.es (M.A.O.).

*E-mail: nlopez@iciq.es (N.L.).

\section{ORCID}

Manuel A. Ortuño: 0000-0002-6175-3941

Núria López: 0000-0001-9150-5941

Notes

The authors declare no competing financial interest.

\section{ACKNOWLEDGMENTS}

M.A.O. and N.L. acknowledge MINECO (CTQ2015-68770) for financial support and BSC-RES for computational resources. M.A.O. also acknowledges the "Juan de la Cierva-Incorporación” postdoctoral program (IJCI-2016-29762).

\section{REFERENCES}

(1) Boles, M. A.; Ling, D.; Hyeon, T.; Talapin, D. V. The Surface Science of Nanocrystals. Nat. Mater. 2016, 15, 141-153.

(2) Zeng, C.; Chen, Y.; Kirschbaum, K.; Lambright, K. J.; Jin, R. Emergence of Hierarchical Structural Complexities in Nanoparticles and Their Assembly. Science 2016, 354, 1580-1584. 
(3) Witham, C. A.; Huang, W.; Tsung, C.-K.; Kuhn, J. N.; Somorjai, G. A.; Toste, F. D. Converting Homogeneous to Heterogeneous in Electrophilic Catalysis using Monodisperse Metal Nanoparticles. Nat. Chem. 2010, 2, 36-41.

(4) Lindlar, H. US Patent 1954, 2681938.

(5) BASF NanoSelect. Witte, P. T. WO patent, 2009, 096783.

(6) Amiens, C.; Ciuculescu-Pradines, D.; Philippot, K. Controlled Metal Nanostructures: Fertile Ground for Coordination Chemists. Coord. Chem. Rev. 2016, 308, 409-432.

(7) Heinz, H.; Pramanik, C.; Heinz, O.; Ding, Y.; Mishra, R. K.; Marchon, D.; Flatt, R. J.; Estrela-Lopis, I.; Llop, J.; Moya, S.; Ziolo, R. F. Nanoparticle Decoration with Surfactants: Molecular Interactions, Assembly, and Applications. Surf. Sci. Rep. 2017, 72, $1-58$.

(8) Albani, D.; Li, Q.; Vilé, G.; Mitchell, S.; Almora-Barrios, N.; Witte, P. T.; López, N.; Pérez-Ramírez, J. Interfacial Acidity in LigandModified Ruthenium Nanoparticles Boosts the Hydrogenation of Levulinic Acid to Gamma-Valerolactone. Green Chem. 2017, 19, 2361-2370.

(9) Zhang, L.; Vogel, Y. B.; Noble, B. B.; Gonçales, V. R.; Darwish, N.; Le Brun, A.; Gooding, J. J.; Wallace, G. G.; Coote, M. L.; Ciampi, S. TEMPO Monolayers on Si(100) Electrodes: Electrostatic Effects by the Electrolyte and Semiconductor Space-Charge on the Electroactivity of a Persistent Radical. J. Am. Chem. Soc. 2016, 138, 96119619.

(10) Aragonés, A. C.; Haworth, N. L.; Darwish, N.; Ciampi, S.; Bloomfield, N. J.; Wallace, G. G.; Diez-Perez, I.; Coote, M. L. Electrostatic Catalysis of a Diels-Alder Reaction. Nature 2016, 531, $88-91$.

(11) Almora-Barrios, N.; Vilé, G.; Garcia-Ratés, M.; Pérez-Ramírez, J.; López, N. Electrochemical Effects at Surfactant-Platinum Nanoparticle Interfaces Boost Catalytic Performance. ChemCatChem 2017, 9, 604-609.

(12) Dodds, D. R.; Gross, R. Chemicals from Biomass. Science 2007, $318,1250-1251$.

(13) Vennestrøm, P. N. R.; Osmundsen, C. M.; Christensen, C. H.; Taarning, E. Beyond Petrochemicals: the Renewable Chemicals Industry. Angew. Chem., Int. Ed. 2011, 50, 10502-10509.

(14) Dawes, G. J. S.; Scott, E. L.; Le Nôtre, J.; Sanders, J. P. M.; Bitter, J. H. Deoxygenation of Biobased Molecules by Decarboxylation and Decarbonylation - A Review on the Role of Heterogeneous, Homogeneous and Bio-catalysis. Green Chem. 2015, 17, 3231-3250.

(15) Santillan-Jimenez, E.; Crocker, M. J. Catalytic Deoxygenation of Fatty Acids and Their Derivatives to Hydrocarbon Fuels via Decarboxylation/Decarbonylation. J. Chem. Technol. Biotechnol. 2012, 87, 1041-1050.

(16) Gosselink, R. W.; Hollak, S. A. W.; Chang, S.-W.; van Haveren, J.; de Jong, K. P.; Bitter, J. H.; van Es, D. S. Reaction Pathways for the Deoxygenation of Vegetable Oils and Related Model Compounds. ChemSusChem 2013, 6, 1576-1594.

(17) Chatterjee, A.; Eliasson, S. H. H.; Jensen, V. R. Selective Production of Linear $\alpha$-Olefins via Catalytic Deoxygenation of Fatty Acids and Derivatives. Catal. Sci. Technol. 2018, 8, 1487-1499.

(18) Arpe, H. J.; Hawkins, S. Industrial Organic Chemistry, $5^{\text {th }}$ ed.; Wiley-VCH Verlag GmbH: Weinheim, Germany, 2010.

(19) Speiser, F.; Braunstein, P.; Saussine, L. Catalytic Ethylene Dimerization and Oligomerization: Recent Developments with Nickel Complexes Containing P,N-Chelating Ligands. Acc. Chem. Res. 2005, 38, 784-793.

(20) McGuinness, D. S. Olefin Oligomerization via Metallacycles: Dimerization, Trimerization, Tetramerization, and Beyond. Chem. Rev. 2011, 111, 2321-2341.

(21) Dry, M. E. The Fischer-Tropsch process: 1950-2000. Catal. Today 2002, 71, 227-241.

(22) Foglia, T. A.; Barr, P. A. Decarbonylation Dehydration of Fatty Acids to Alkenes in the Presence of Transition Metal Complexes. J. Am. Oil Chem. Soc. 1976, 53, 737-741.

(23) Miller, J. A.; Nelson, J. A.; Byrne, M. P. A Highly Catalytic and Selective Conversion of Carboxylic Acids to 1-Alkenes of One Less Carbon Atom. J. Org. Chem. 1993, 58, 18-20.
(24) Gooßen, L. J.; Rodríguez, N. A Mild and Efficient Protocol for the Conversion of Carboxylic Acids to Olefins by a Catalytic Decarbonylative Elimination Reaction. Chem. Commun. 2004, 724725 .

(25) Le Nôtre, J.; Scott, E. L.; Franssen, M. C. R.; Sanders, J. P. M. Selective Preparation of Terminal Alkenes from Aliphatic Carboxylic Acids by a Palladium-catalysed Decarbonylation-Elimination Reaction. Tetrahedron Lett. 2010, 51, 3712-3715.

(26) Kraus, G. A.; Riley, S. A Large-Scale Synthesis of $\alpha$-Olefins and $\alpha, \omega$-Dienes. Synthesis 2012, 44, 3003-3005.

(27) Miranda, M. O.; Pietrangelo, A.; Hillmyer, M. A.; Tolman, W. B. Catalytic Decarbonylation of Biomass-derived Carboxylic Acids as Efficient Route to Commodity Monomers. Green Chem. 2012, 14, 490-494.

(28) Liu, Y.; Kim, K. E.; Herbert, M. B.; Fedorov, A.; Grubbs, R. H.; Stoltz, B. M. Palladium-Catalyzed Decarbonylative Dehydration of Fatty Acids for the Production of Linear Alpha Olefins. Adv. Synth. Catal. 2014, 356, 130-136.

(29) Chatterjee, A.; Eliasson, S. H. H.; Tornroos, K. W.; Jensen, V. R. Palladium Precatalysts for Decarbonylative Dehydration of Fatty Acids to Linear Alpha Olefins. ACS Catal. 2016, 6, 7784-7789.

(30) John, A.; Dereli, B.; Ortuño, M. A.; Johnson, H. E.; Hillmyer, M. A.; Cramer, C. J.; Tolman, W. B. Selective Decarbonylation of Fatty Acid Esters to Linear $\alpha$-Olefins. Organometallics 2017, 36, 2956-2964.

(31) John, A.; Miranda, M. O.; Ding, K.; Dereli, B.; Ortuño, M. A.; LaPointe, A. M.; Coates, G. W.; Cramer, C. J.; Tolman, W. B. Nickel Catalysts for the Dehydrative Decarbonylation of Carboxylic Acids to Alkenes. Organometallics 2016, 35, 2391-2400.

(32) Snåre, M.; Kubičková, I.; Mäki-Arvela, P.; Eränen, K.; Murzin, D. Y. Heterogeneous Catalytic Deoxygenation of Stearic Acid for Production of Biodiesel. Ind. Eng. Chem. Res. 2006, 45, 5708-5715.

(33) Snåre, M.; Kubičková, I.; Mäki-Arvela, P.; Eränen, K.; Wärnå, J.; Murzin, D. Y. Production of Diesel Fuel from Renewable Feeds: Kinetics of Ethyl Stearate Decarboxylation. Chem. Eng. J. 2007, 134, 29-34.

(34) Immer, J. G.; Kelly, M. J.; Lamb, H. H. Catalytic Reaction Pathways in Liquid-phase Deoxygenation of C18 Free Fatty Acids. Appl. Catal., A 2010, 375, 134-139.

(35) Ford, J. P.; Immer, J. G.; Lamb, H. H. Palladium Catalysts for Fatty Acid Deoxygenation: Influence of the Support and Fatty Acid Chain Length on Decarboxylation Kinetics. Top. Catal. 2012, 55, 175-184.

(36) Sun, K.; Wilson, A. R.; Thompson, S. T.; Lamb, H. H. Catalytic Deoxygenation of Octanoic Acid over Supported Palladium: Effects of Particle Size and Alloying with Gold. ACS Catal. 2015, 5, 1939-1948.

(37) Hollak, S. A. W.; Bitter, J. H.; van Haveren, J.; de Jong, K. P.; van Es, D. S. Selective Deoxygenation of Stearic Acid via an Anhydride Pathway. RSC Adv. 2012, 2, 9387-9391.

(38) Lopez-Ruiz, J. A.; Davis, R. J. Decarbonylation of Heptanoic Acid over Carbon-supported Platinum Nanoparticles. Green Chem. 2014, 16, 683-694.

(39) Lopez-Ruiz, J. A.; Pham, H. N.; Datye, A. K.; Davis, R. J. Reactivity and Stability of Supported Pd Nanoparticles during the Liquid-phase and Gas-phase Decarbonylation of Heptanoic Acid. Appl. Catal., A 2015, 504, 295-307.

(40) Li, W.; Gao, Y.; Yao, S.; Ma, D.; Yan, N. Effective Deoxygenation of Fatty Acids over $\mathrm{Ni}(\mathrm{OAc})_{2}$ in the Absence of $\mathrm{H}_{2}$ and Solvent. Green Chem. 2015, 17, 4198-4205.

(41) Chatterjee, A.; Jensen, V. R. A Heterogeneous Catalyst for the Transformation of Fatty Acids to $\alpha$-Olefins. ACS Catal. 2017, 7, 2543-2547.

(42) Tamura, M.; Fujihara, H. Chiral Bisphosphine BINAP-stabilized Gold and Palladium Nanoparticles with Small Size and Their Palladium Nanoparticle-catalyzed Asymmetric Reaction. J. Am. Chem. Soc. 2003, 125, 15742-15743.

(43) Tatumi, R.; Akita, T.; Fujihara, H. Synthesis of Small Palladium Nanoparticles Stabilized by Bisphosphine BINAP Bearing an Alkyl Chain and Their Palladium Nanoparticle-catalyzed Carbon-Carbon 
Coupling Reactions Under Room-temperature. Chem. Commun. 2006, 3349-3351.

(44) Ortuño, M. A.; Dereli, B.; Cramer, C. J. Mechanism of Pdcatalyzed Decarbonylation of Biomass-derived Hydrocinnamic Acid to Styrene Following Activation as an Anhydride. Inorg. Chem. 2016, 55, 4124-4131.

(45) Eliasson, S. H. H.; Chatterjee, A.; Occhipinti, G.; Jensen, V. R. The Mechanism of Rh-Catalyzed Transformation of Fatty Acids to Linear Alpha olefins. Inorganics 2017, 5, 87.

(46) Lu, J.; Behtash, S.; Heyden, A. Theoretical Investigation of the Reaction Mechanism of the Decarboxylation and Decarbonylation of Propanoic Acid on Pd (111) Model Surfaces. J. Phys. Chem. C 2012, 116, 14328-14341.

(47) Lu, J.; Behtash, S.; Faheem, M.; Heyden, A. Microkinetic Modeling of the Decarboxylation and Decarbonylation of Propanoic Acid over Pd(111) Model Surfaces Based on Parameters Obtained from First Principles. J. Catal. 2013, 305, 56-66.

(48) Behtash, S.; Lu, J.; Faheem, M.; Heyden, A. Solvent Effects on the Hydrodeoxygenation of Propanoic Acid over Pd(111) Model Surfaces. Green Chem. 2014, 16, 605-616.

(49) Lugo-José, Y. K.; Behtash, S.; Nicholson, M.; Monnier, J. R.; Heyden, A.; Williams, C. T. Unraveling the Mechanism of Propanoic Acid Hydrodeoxygenation on Palladium Using Deuterium Kinetic Isotope Effects. J. Mol. Catal. A: Chem. 2015, 406, 85-93.

(50) Behtash, S.; Lu, J.; Heyden, A. Theoretical Investigation of the Hydrodeoxygenation of Methyl Propionate over $\operatorname{Pd}(111)$ Model Surfaces. Catal. Sci. Technol. 2014, 4, 3981-3992.

(51) Behtash, S.; Lu, J.; Walker, E.; Mamun, O.; Heyden, A. Solvent Effects in the Liquid Phase Hydrodeoxygenation of Methyl Propionate over a Pd(111) Catalyst Model. J. Catal. 2016, 333, 171-183.

(52) Behtash, S.; Lu, J.; Williams, C. T.; Monnier, J. R.; Heyden, A. Effect of Palladium Surface Structure on the Hydrodeoxygenation of Propanoic Acid: Identification of Active Sites. J. Phys. Chem. C 2015, $119,1928-1942$

(53) Behtash, S.; Lu, J.; Mamun, O.; Williams, C. T.; Monnier, J. R.; Heyden, A. Solvation Effects in the Hydrodeoxygenation of Propanoic Acid over a Model Pd(211) Catalyst. J. Phys. Chem. C 2016, 120, 2724-2736.

(54) Lu, J.; Faheem, M.; Behtash, S.; Heyden, A. Theoretical Investigation of the Decarboxylation and Decarbonylation Mechanism of Propanoic Acid over a $\mathrm{Ru}(0001)$ Model Surface. J. Catal. 2015, 324, 14-24.

(55) Reimann, S.; Urakawa, A.; Baiker, A. BINAP Adsorption on Palladium: A Combined Infrared Spectroscopy and Theoretical Study. J. Phys. Chem. C 2010, 114, 17836-17844.

(56) Fresch, B.; Remacle, F. Tuning the Properties of Pd Nanoclusters by Ligand Coatings: Electronic Structure Computations on Phosphine, Thiol, and Mixed Phosphine-Thiol Ligand Shells. J. Phys. Chem. C 2014, 118, 9790-9800.

(57) Pei, Y.; Shao, N.; Gao, Y.; Zeng, X. C. Investigating Active Site of Gold Nanoparticle $\mathrm{Au}_{55}\left(\mathrm{PPh}_{3}\right)_{12} \mathrm{Cl}_{6}$ in Selective Oxidation. ACS Nano 2010, 4, 2009-2020.

(58) Cano, I.; Chapman, A. M.; Urakawa, A.; van Leeuwen, P. W. N. M. Air-stable Gold Nanoparticles Ligated by Secondary Phosphine Oxides for the Chemoselective Hydrogenation of Aldehydes: Crucial Role of the Ligand. J. Am. Chem. Soc. 2014, 136, 2520-2528.

(59) Almora-Barrios, N.; Cano, I.; van Leeuwen, P. W. N. M.; López, N. Concerted Chemoselective Hydrogenation of Acrolein on Secondary Phosphine Oxide Decorated Gold Nanoparticles. ACS Catal. 2017, 7, 3949-3954.

(60) Kresse, G.; Furthmuller, J. Efficient Iterative Schemes for Ab Initio Total-energy Calculations Using a Plane-wave Basis Set. Phys. Rev. B: Condens. Matter Mater. Phys. 1996, 54, 11169-11186.

(61) Kresse, G.; Furthmüller, J. Efficiency of Ab-initio Total Energy Calculations for Metals and Semiconductors Using a Plane-wave Basis Set. Comput. Mater. Sci. 1996, 6, 15-50.

(62) Perdew, J. P.; Burke, K.; Ernzerhof, M. Generalized Gradient Approximation Made Simple. Phys. Rev. Lett. 1996, 77, 3865-3868.
(63) Grimme, S. Semiempirical GGA-type Density Functional Constructed with a Long-range Dispersion Correction. J. Comput. Chem. 2006, 27, 1787-1799.

(64) Almora-Barrios, N.; Carchini, G.; Błoński, P.; López, N. Costless Derivation of Dispersion Coefficients for Metal Surfaces. J. Chem. Theory Comput. 2014, 10, 5002-5009.

(65) Kresse, G.; Joubert, D. From Ultrasoft Pseudopotentials to the Projector Augmented-wave Method. Phys. Rev. B: Condens. Matter Mater. Phys. 1999, 59, 1758-1775.

(66) Monkhorst, H. J.; Pack, J. D. Special Points for Brillouin-zone Integrations. Phys. Rev. B 1976, 13, 5188-5192.

(67) Makov, G.; Payne, M. C. Periodic Boundary Conditions in Ab Initio Calculations. Phys. Rev. B: Condens. Matter Mater. Phys. 1995, 51, 4014-4022.

(68) Henkelman, G.; Jónsson, H. Improved Tangent Estimate in the Nudged Elastic Band Method for Finding Minimum Energy Paths and Saddle Points. J. Chem. Phys. 2000, 113, 9978-9985.

(69) Heyden, A.; Bell, A. T.; Keil, F. J. Efficient Methods for Finding Transition States in Chemical Reactions: Comparison of Improved Dimer Method and Partitioned Rational Function Optimization Method. J. Chem. Phys. 2005, 123, 224101.

(70) Ribeiro, R. F.; Marenich, A. V.; Cramer, C. J.; Truhlar, D. G. Use of Solution-phase Vibrational Frequencies in Continuum Models for the Free Energy of Solvation. J. Phys. Chem. B 2011, 115, 1455614562 .

(71) Alvarez-Moreno, M.; De Graaf, C.; López, N.; Maseras, F.; Poblet, J. M.; Bo, C. Managing the Computational Chemistry Big Data Problem: the ioChem-BD Platform. J. Chem. Inf. Model. 2015, 55, 95103.

(72) Ortuño, M. A. Database DOI: 10.19061/iochem-bd-1-70.

(73) Tarini, M.; Cignoni, P.; Montani, C. Ambient Occlusion and Edge Cueing for Enhancing Real Time Molecular Visualization. IEEE Trans. Vis. Comput. Graph. 2006, 12, 1237-1244.

(74) Other isomers were found within $0.02 \mathrm{eV}$ of $\mathbf{A 1}$.

(75) Pallassana, V.; Neurock, M.; Coulston, G. W. Theoretical Density Functional Analysis of Maleic Anhydride Chemisorption on $\mathrm{Pd}(111), \operatorname{Re}(0001)$, and Bimetallic $\mathrm{Pd}_{\mathrm{ML}} / \operatorname{Re}(0001)$ and $\mathrm{Pd}_{\mathrm{ML}} /$ Mo(110) Pseudomorphic Overlayers. J. Phys. Chem. B 1999, 103, 8973-8983.

(76) Mahapatra, M.; Tysoe, W. T. Local and Extended Structures of D-(-)-Tartaric Acid on Pd(111). J. Phys. Chem. C 2016, 120, 23092319.

(77) Kumar, G.; Lien, C.-H.; Janik, M. J.; Medlin, J. W. Catalyst Site Selection via Control over Noncovalent Interactions in Self-Assembled Monolayers. ACS Catal. 2016, 6, 5086-5094.

(78) González-Gálvez, D.; Nolis, P.; Philippot, K.; Chaudret, B.; van Leeuween, P. W. N. M. Phosphine-stabilized Ruthenium Nanoparticles: the Effect of the Nature of the Ligand in Catalysis. ACS Catal. 2012, 2, 317-321.

(79) Martínez-Prieto, L. M.; Cano, I.; Márquez, A.; Baquero, E. A.; Tricard, S.; Cusinato, L.; del Rosal, I.; Poteau, R.; Coppel, Y.; Philippot, K.; Chaudret, B.; Cámpora, J.; van Leeuwen, P. W. N. M. Zwitterionic Amidinates as Effective Ligands for Platinum Nanoparticle Hydrogenation Catalysts. Chem. Sci. 2017, 8, 2931-2941.

(80) Fiorio, J. L.; López, N.; Rossi, L. M. Gold-Ligand-Catalyzed Selective Hydrogenation of Alkynes into cis-Alkenes via $\mathrm{H}_{2}$ Heterolytic Activation by Frustrated Lewis Pairs. ACS Catal. 2017, 7, 2973-2980.

(81) The estimated Gibbs energy difference at $523 \mathrm{~K}$ is $1.21 \mathrm{eV}$.

(82) Other isomers were found at $\sim 1.4 \mathrm{eV}$ above $\mathrm{C}$.

(83) Adams, G. M.; Weller, A. S. POP-type ligands: Variable Coordination and Hemilabile Behavior. Coord. Chem. Rev. 2018, 355, 150-172.

(84) The estimated activation Gibbs energy at $523 \mathrm{~K}$ is $1.12 \mathrm{eV}$.

(85) $\alpha$-Carbon dehydrogenation ${ }^{46}$ of the acyl group C3 is endothermic by $1.05 \mathrm{eV}$ (C8) and has a barrier of $1.50 \mathrm{eV}$ (TSC3-8).

(86) A barrier of $1.72 \mathrm{eV}$ was found through an isomer of C4 involving the rotation of the alkyl chain (from C4a to TS-C4a). 
(87) Hammer, B.; Nørskov, J. K. Electronic Factors Determining the Reactivity of Metal Surfaces. Surf. Sci. 1995, 343, 211-220.

(88) Hammer, B.; Nørskov, J. K. Theoretical Surface Science and Catalysis-Calculations and Concepts. Adv. Catal. 2000, 45, 71-129.

(89) Madsen, A. T.; Rozmysłowicz, B.; Simakova, I. L.; Kilpiö, T.; Leino, A.-R.; Kordás, K.; Eränen, K.; Mäki-Arvela, P.; Murzin, D. Y. Step Changes and Deactivation Behavior in the Continuous Decarboxylation of Stearic Acid. Ind. Eng. Chem. Res. 2011, 50, 11049-11058.

(90) Huang, Y.-B.; Yang, Z.; Chen, M.-Y.; Dai, J.-J.; Guo, Q.-X.; Fu, Y. Heterogeneous Palladium Catalysts for Decarbonylation of Biomass-Derived Molecules under Mild Conditions. ChemSusChem 2013, 6, 1348-1351.

(91) Schoenbaum, C. A.; Schwartz, D. K.; Medlin, J. W. Controlling the Surface Environment of Heterogeneous Catalysts Using SelfAssembled Monolayers. Acc. Chem. Res. 2014, 47, 1438-1445.

(92) Zhang, J.; Ellis, L. D.; Wang, B.; Dzara, M. J.; Sievers, C.; Pylypenko, S.; Nikolla, E.; Medlin, J. W. Control of Interfacial AcidMetal Catalysis with Organic Monolayers. Nat. Catal. 2018, 1, 148155.

(93) Vorotnikov, V.; Mpourmpakis, G.; Vlachos, D. G. DFT Study of Furfural Conversion to Furan, Furfuryl Alcohol, and 2-Methylfuran on $\operatorname{Pd}(111)$. ACS Catal. 2012, 2, 2496-2504.

(94) Wang, S.; Vorotnikov, V.; Vlachos, D. G. Coverage-induced Conformational Effects on Activity and Selectivity: Hydrogenation and Decarbonylation of Furfural on $\operatorname{Pd}(111)$. ACS Catal. 2015, 5, 104112.

(95) Fiorio, J. L.; Gonçalves, R. V.; Teixeira-Neto, E.; Ortuño, M. A.; López, N.; Rossi, L. M. Accessing Frustrated Lewis Pair Chemistry Through Robust Gold@N-doped Carbon for Selective Hydrogenation of Alkynes. ACS Catal. 2018, 8, 3516-3524.

(96) Fanjul, T.; Eastham, G.; Haddow, M. F.; Hamilton, A.; Pringle, P. G.; Orpen, A. G.; Turner, T. P. W.; Waugh, M. Efficient and Chemoselective Ethene Hydromethoxycarbonylation Catalysts based on Pd-complexes of Heterodiphosphines o- $\mathrm{C}_{6} \mathrm{H}_{4}\left(\mathrm{CH}_{2} \mathrm{P}^{\mathrm{t}} \mathrm{Bu}_{2}\right)$ $\left(\mathrm{CH}_{2} \mathrm{PR}_{2}\right)$. Catal. Sci. Technol. 2012, 2, 937-950.

(97) Dong, K.; Fang, X.; Gülak, S.; Franke, R.; Spannenberg, A.; Neumann, H.; Jackstell, R.; Beller, M. Highly Active and Efficient Catalysts for Alkoxycarbonylation of Alkenes. Nat. Commun. 2017, 8, 14117.

(98) Nørskov, J. K.; Bligaard, T.; Rossmeisl, J.; Christensen, C. H. Towards the Computational Design of Solid Catalysts. Nat. Chem. 2009, 1, 37-46. 